\title{
Patients with chronic obstructive pulmonary disease treated by the mobile emergency care unit - hospitalization and prognostic factors
}

\author{
KP Lindvig ${ }^{1 *}$, AC Brøchner ${ }^{2}$, AT Lassen ${ }^{3}$, S Mikkelsen $^{2}$ \\ From ESICM LIVES 2015 \\ Berlin, Germany. 3-7 October 2015
}

\begin{abstract}
Introduction
Chronic Obstructive Pulmonary Disease (COPD) is an important and increasing cause of morbidity and mortality worldwide. Patients with COPD suffer from acute exacerbations (AE), which lead to a reduced quality of life, increased risk of mortality, further and longer hospitalization, and increased healthcare costs.
\end{abstract}

\section{Objectives}

The aims of the study are to describe patients with $\mathrm{AE}$ admitted through the Mobile Emergency Care Unit (MECU), to identify prognostic factors and to determine the associated 30-day mortality.

\section{Methods}

The study was performed in the MECU in Odense Denmark, from the $1^{\text {st }}$ of July $2011-31^{\text {st }}$ of December 2013. All first-time contact patients ( $>18$ years) with COPD treated by the MECU within this period were eligible for the study. AE diagnosis were confirmed by patient record review otherwise the patient was excluded from the study.

\section{Results}

Within the study period of 2 years and 5 months, 438 patients with $\mathrm{AE}$ were treated by the MECU, hereof 264 (60.3\%) patients were first-time contacts, and thus eligible for inclusion in the study. Furthermore, the MECU had 174 (39.7\%) additional patient contacts with AE within the study period. Of the 264 included first-time contacts, $113(42.8 \%)$ were male, and the mean age was 72.4 years. 159 (60.2\%) had severely affected breathing

${ }^{1}$ University of Southern Denmark, Odense C, Denmark

Full list of author information is available at the end of the article upon arrival of the MECU. 7 patients (2.6\%) were intubated in the prehospital setting. 262 (99.2\%) of all patients with AE in contact with the MECU were admitted to hospital, and only $2(0.76 \%)$ patients were left at scene, this might be due to the fact that only first-time contacts were included in the study. Patients were hospitalized on average 5.3 days (0-48). 22 of $264(8.3 \%)$ patients were transferred to the intensive care unit (ICU) with an average stay of 2.6 days (56.6 hours), of these 22 patients, 21 (95.5\%) were mechanically ventilated on average 38.7 hours. $7 / 22$ (31.8\%) of patients admitted to ICU were dead within 30 days. The overall 30-day mortality among patients with $\mathrm{AE}$ was $12.5 \%(33 / 264)$. In a multivariate Cox regression model, age $>80$ years HR $0.8(0.2-3.0)$ and female sex HR 0.8 (0.4-1.9) were analyzed as prognostic factors of mortality among patients with AE, however were found non-significant at a $95 \%$ confidence level.

\section{Conclusions}

We found that among first-time contact patients with $\mathrm{AE}$ treated by the MECU, a small proportion of these patients are admitted to ICU to receive mechanical ventilation. However one third of these patients die within 30 days. Despite non-significant levels, data indicate that when admitted to hospital due to $\mathrm{AE}$, being male sex and of younger age worsens the prognosis.

\footnotetext{
Authors' details

${ }^{1}$ University of Southern Denmark, Odense C, Denmark. ${ }^{2}$ Institute of Clinical Research, University of Southern Denmark, Mobile Emergency Care Unit, Department of Anaesthesiology and Intensive Care, Odense C, Denmark. ${ }^{3}$ Department of Emergency Medicine Odense University Hospital, Odense C, Denmark.
} 


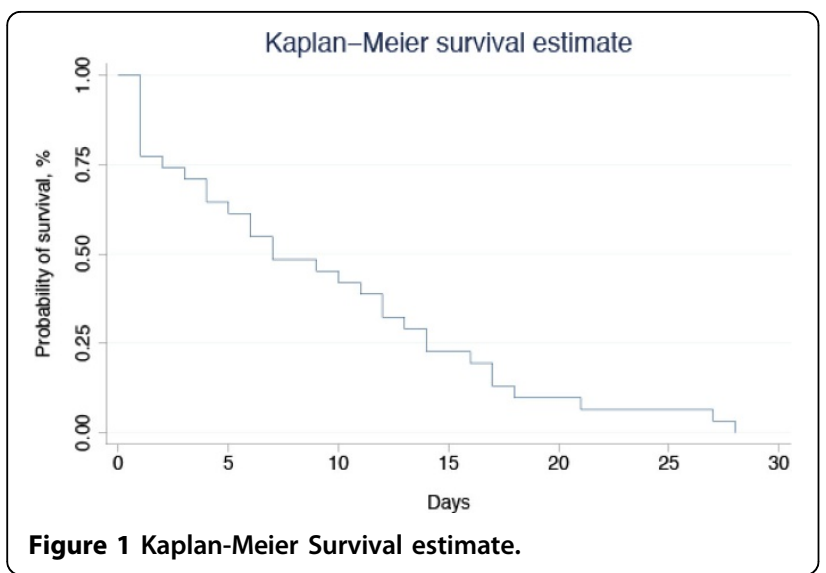

Published: 1 October 2015

doi:10.1186/2197-425X-3-S1-A393

Cite this article as: Lindvig et al:: Patients with chronic obstructive

pulmonary disease treated by the mobile emergency care unit -

hospitalization and prognostic factors. Intensive Care Medicine

Experimental 2015 3(Suppl 1):A393.

\section{Submit your manuscript to a SpringerOpen ${ }^{\mathcal{O}}$ journal and benefit from:}

- Convenient online submission

- Rigorous peer review

- Immediate publication on acceptance

- Open access: articles freely available online

- High visibility within the field

- Retaining the copyright to your article

Submit your next manuscript at $\gg$ springeropen.com 